\title{
The Fourth Industrial Revolution: Will it change pharmacy practice?
}

Schwab (2017) argues that society is at the beginning of a Fourth Industrial Revolution (4IR). This era will radically change the human use of technology, with major implications for the ways we live and work. The first industrial revolution started after 1760 and led the move from hand production to machines, which created many new industrial processes including chemical manufacturing. The second revolution occurred after 1870 and was initially stimulated by new methods for the mass production of steel, but then spread to the developments in other industries such as chemicals and transport. The third revolution (the "Digital Age") began in the 1960s with the development of electronics, information technology (IT) and automated production. We are now entering the 4IR, which will create innovative capabilities for people and machines through the adoption of technologies such as cyber-physical systems, the Internet of Things (IOTs) and the Internet of Systems (Gatouillat et. al., 2018).

Throughout its history, pharmacy has successfully adopted a range of "general purpose technologies" (GPTs) that were developed during the first three industrial revolutions. GPTs are defined as technologies that affect an entire economy and have the potential to disrupt the economic life of whole societies.(Helpman, 1998) To date, only 24 GPTs have emerged, including the steam engine, trains, electricity, computing, the internet, artificial intelligent and blockchain.(Lipsey et. al., 2005). During their history, apothecaries, chemists and druggists and modern-day pharmacists have all used GPTs to: create the pharmaceutical industry; invent new processes for making dyes; improve brewing techniques; advance photography and film-making; introduce robotic and barcode dispensing; harness sensor technology in dossetts and pill boxes. As this list suggests, pharmacy evolved because of its industrial-scale adoption of GDPs from the first three revolutions. The key question, therefore, how can we make this trend continue during the fourth wave?

For all industrial sectors, the consequences of the 4IR are predicted to be unprecedented. Schwab (2017, p.2) describes the potential risks and benefits: 
The changes are so profound that, from the perspective of human history, there has never been a time of greater promise or potential peril. My concern, however, is that decision-makers are too often caught in traditional, linear (and non-disruptive) thinking or too absorbed by immediate concerns to think strategically about the forces of disruption and innovation shaping our future.

Just as these words apply to all industries, Schwab's message also applies to pharmacy. If the pharmacy sector is stuck in traditional, linear thinking that assumes the future will be an extension of the past, then the fourth revolution may be less of a promise and more of a threat. In consequence, outsiders may take over many activities that have traditionally been considered to be solely pharmacy work. For instance, online dispensaries may move business away from local "bricks and mortar" pharmacies. Phone apps may replace the need for face-to-face pharmaceutical care, with online platforms for patient counselling. In response, there is a pressing need for the pharmacy sector as a whole to consider how fourth wave technologies will affect the future of its clinical and commercial activities.

\section{Technology types}

Writing about pharmacy, Baines et. al. (2018a) defines "technology' as the "dynamic clustering of techniques, methods, skills and processes used in the production of goods or services or in the achievement of outcomes that deliver desired benefits for consumers". This definition suggest the fourth wave technologies could: (i) help pharmacists do what they currently do better, (ii) extend the range of outcomes the profession is able to produce, (iii) a combination of both. However, a technology is not just a cultural product, but in itself a producer of culture (Nørgaard et. al., 2001). This should be taken into account, when we try to grasp the meaning of the technology as part of the future in pharmacy.(Baines, 2015a) For instance, dispensing, patient counselling and the delivery of services could be made more cost-effective by technologies such as mobile phone apps. Similarly, pharmacy could extend its services into data analytics using Big Data. If no competition exists, fourth wave technologies may promote a viable future by creating a more efficient, expansive pharmacy sector. Applying technologies may support pharmacy 
as a valid player in the healthcare sector. However, the sector as a whole faces the “innovator's dilemma" when responding to 4IR. Should the pharmacy profession disrupt their current activities in order to: (i) do things better, (ii) do new things, and (iii) deter competition? We believe that these are pressing issues in need of widespread debate.

\section{Pharmaceutical care}

Leading pharmacists are aware that technology can disrupt society and the economics of pharmacy. Over thirty years ago, Hepler (1988) argued that technology, economics and social values are the major forces shaping pharmacy's future. Amongst the technological forces shaping pharmacy practice, Helper cited computers, robotics, communications and therapeutics as the stimulants of change. Amongst the important economic factors, he listed managed care, payment for outcomes and the marketing services as the factors most likely to have the largest effect. Finally, Hepler believed that an aging population, the weakening of professional authority and a deterioration in pharmacy's public image were having the biggest social impact on the profession. In response, he argued that pharmacists should return to their fundamental relationship with society by accepting the ethical responsibility for drug-use control. To accomplish this goal, pharmacy would need to undergo a process of occupational reconstruction and self-renewal in order to become providers of a new societal model of practice, which Hepler and Strand (1990, p.539) refer to as "pharmaceutical care". They state:

Pharmaceutical care is the responsible provision of drug therapy for the purpose of achieving definite outcomes that improve a patient's quality of life. These outcomes are: (1) cure of a disease, (2) elimination or reduction of a patient's symptomatology, (3) arresting or slowing of a disease process, or (4) preventing a disease or symptomatology.

Pharmaceutical care was developed during the third industrial revolution. In the last thirty years, advances in computing, robotics, communications and therapeutics have all been stimulants of change. For instance, most pharmacies are computerized, just as robotics 
dispensing is growing fast in use. The question, therefore, arises: how will pharmacy respond to the opportunities and challenges offered by the 4IR?

In the healthcare sector, the 4IR revolution is happening much faster outside of pharmacy than within. Where the targets of innovation are medicines supply or advice, the main developers and players involved in the 4IR? tend not to be pharmacists. This raises serious questions about the future development of the pharmacy sector.(Rossing, 2018) For instance, what will happen to local pharmacies if most dispensing moves online? What is the professional role of the pharmacy if dispensing disappears? After thirty years of struggling to establish clinical pharmacy as a viable model of practice, what will happen to patient counselling if innovative technologies bypass pharmacy and go straight to consumers? In response to such questions, we believe that stakeholders in pharmacy should engage in open discussion about the opportunities and threats of the 4IR.

\section{Health technology}

The World Health Organization defines "health technology" as the "application of organized knowledge and skills in the form of devices, medicines, vaccines, procedures and systems developed to solve a health problem and improve quality of lives". This definition goes beyond the everyday definition of "technology" as manufactured objects such as mobile phones or computing such as Artificial Intelligence (AI) used by human beings either for their own personal ends or for the production of goods and services for sale (Feenberg, 1991; Vyas et. al., 2018). Researchers from the science technology society argue that the term technology contains at least three components, which are to be present simultaneously in order for a piece of technique to be functioning, namely: (i) hardware (tools, machines, devices), (ii) knowledge (knowledge and knowledge interest embodied in the hardware) and (iii) organization (the ensuing systematic procedures or mode of work which goes with the use of the hardware (Nørgaard 1996; MacKenzie and Wajcman, 1985). These technology definitions all include the wider dynamic surrounding the use of technologies to include the actions of humans using clinical procedures and health systems to help create wellbeing and quality of life. In response, pharmacists would benefit from 
viewing technologies as embedded in, and inseparable from, the overall production processes that supply drugs and generate patient wellbeing (Baines et. al., 2018b).

Traditionally, pharmacy has based its operational procedures for dispensing and pharmaceutical care on the assumption that patients will interact with pharmacists face-toface. According to Schwab, fourth wave technologies will advance communications and connectivity in ways that connect billions of people to the internet in innumerable ways. Future developments in internet-based technologies could remove pharmacists from the process of care delivery. In other words, 4IR could disrupt physical, on-the-ground networks between doctors, patients and pharmacists and create cyber, in-the-cloud connections that promote "direct-to-consumer pharmacy". For instance, Big Data and AI could identify patient needs, track medicines usage and search for pharmaceutical problems. All of this could happen automatically based upon algorithms and specified treatment routines, without the input from pharmacists in real time. Moreover, these services could be provided outside of traditional pharmacy locations (such as community and hospital pharmacies), existing only in cyberspace with no or only limited face-to-face contact.

In developing the pharmaceutical care paradigm, Hepler and Strand were exacting in their analysis of the evolution of pharmacy and forceful in outlining their vision of pharmacy's role in society. Whilst the technological, economic and social challenges they described thirty years ago have moved on, the underlying issue have not really: how should pharmacy re-professionalise itself to create value and wellbeing for patients in an everevolving society? The 4IR has made this question pertinent again. Online, direct-toconsumer pharmacy has the power to disrupt the local, face-to-face networks that have long existed between doctors, patients and pharmacists. In response, we believe that now is the time for a debate about the opportunities and threats to medication safety that will be caused by the disruptive 4IR, with a specific focus on what pharmacy can contribute in a rapidly changing healthcare sector. 
Evidence suggests that external parties will be happy to create a new future for an industry that traditionally has been the monopoly of the profession of pharmacy.(Baines, 2015b) In this context, pharmacy urgently needs a new roadmap, an innovative blueprint in order to survive the disruption ahead.

\section{Conclusions}

Pharmaceutical care was meant as a philosophy of practice. A method of caring for medicines treatment and taking responsibility for patient outcome. Pharmacy was meant to have a supporting role in this process. To uphold this position and take leadership of pharmaceutical care in the future, pharmacy needs to be curious on how to work with AI, Big data, augmented reality, and much more. If the new game is understood, the pharmacist may become the playmaster of tomorrow. 


\section{References}

Baines, D. (2015a). Community pharmacies deserve a renaissance. Int Pharm J 33 (2015): 46-7.

Baines, D. (2015b). If we understand the past we can plan for the future. Prescriber, 26(17), 16-20.

Baines, D., Bates, I., Bader, L., Hale, C., \& Schneider, P. (2018a). Conceptualising production, productivity and technology in pharmacy practice: a novel framework for policy, education and research. Human resources for health, 16(1), 51.

Baines, D. L., Gahir, I. K., Hussain, A., Khan, A. J., Schneider, P., Hasan, S. S., \& Babar, Z. U. D. (2018b). A scoping review of the quality and the design of evaluations of mobile health, telehealth, smart pump and monitoring technologies performed in a pharmacyrelated setting. Frontiers in pharmacology, 9, 678.

Feenberg, A. (1991). Critical theory of technology (Vol. 5). New York: Oxford University Press.

Gatouillat, A., Badr, Y., Massot, B., \& Sejdić, E. (2018). Internet of medical things: A review of recent contributions dealing with cyber-physical systems in medicine. IEEE Internet of Things Journal, 5(5), 3810-3822.

Hepler, C. D. (1988). Unresolved issues in the future of pharmacy. American Journal of Health-System Pharmacy, 45(5), 1071-1081.

Helpman, E. (Ed.). (1998). General purpose technologies and economic growth. MIT press.

Hepler, C. D., \& Strand, L. M. (1990). Opportunities and responsibilities in pharmaceutical care. Am J hosp pharm, 47(3), 533-543.

Lipsey, R. G., Carlaw, K. I., \& Bekar, C. T. (2005). Economic transformations: general purpose technologies and long-term economic growth. OUP Oxford.

MacKenzie, D and Wajcman, J. (eds). (1985). The Social Shaping of Technology. Milton Keynes and Philadelphia: Open University Press. 
Nørgaard LS. The Development of Patient Medication Records in Denmark - a Social Constructivist View. PhD.-thesis. Department of Social Pharmacy, The Royal Danish School of Pharmacy, 1996.

Nørgaard LS, Sørensen EW, Morgall JM. Social constructivist analysis of a patient medication record experiment - why a good idea and good intentions are not enough. International Journal of Pharmacy Practice 2001; 8(4): 237-46.

Rossing, C. (2018). Implementation of pharmaceutical care in community setting. In da Costa, F. A., van Mil, J. F., \& Alvarez-Risco, A. (2018). The Pharmacist Guide to Implementing Pharmaceutical Care.

Schwab, K. (2017). The Fourth Industrial Revolution. Switzerland: World Economic Forum.

Vyas, M., Thakur, S., Riyaz, B., Bansal, K. K., Tomar, B., \& Mishra, V. (2018). Artificial Intelligence: The Beginning of a New Era in Pharmacy Profession. Asian Journal of Pharmaceutics, 12(2), 72-76. 